\title{
COMBINATION APPROACH WITH AMBULATORY BLOOD PRESSURE AND ELECTROCARDIOGRAPHY MONITORING IN PATIENTS WITH HYPERTENSION AND MYOCARDIAL INFARCTION - A PROSPECTIVE STUDY.
}

\author{
Varahabhatla Vamsi $^{1}$, Adunuthula Shrividya ${ }^{1}$, Maganty Virajitha $^{1}$, Vedula Ushakiranmayi ${ }^{2}$, Buriak Viktor Valerivich $^{3}$ \\ ${ }^{1}$ Student, General medicine speciality, Zaporozhye State Medical University, Ukraine \\ ${ }^{2}$ Resident, Konaseema Institute of Medical Sciences, India. \\ ${ }^{3}$ Associate Professor, Department of Internal diseases 2, Zaporozhye State Medical University, Ukraine
}

\section{Abstract}

Introduction: With the increasing number of deaths due to cardiovascular events, there is an urgent need for optimising the risk factors associated with it. The safety and cost effective non-invasive method to assess the blood pressure and modulate the treatment plan accordingly is to utilise the ambulatory blood pressure monitoring and Holter Electrocardiography in daily use in patients with hypertension.

Aim: To examine the functional state of cardiovascular system and possible predictive value of the daily application of the combined method of arterial blood pressure monitoring and ECG monitoring in hypertensive patients at different levels of the disease progression.

Methods and materials: We examined 37 patients with AH without any clinical significant pathology were included in the first group and 32 hypertensive patients with a history of myocardial infarction (MI) in the second group. The average age of participants in this study was 59,02士2,18 years. All patients underwent a comprehensive examination of the functional state of the cardiovascular system using the combined ECG and arterial BP monitoring validated device "CardiosensBP» XAI-MEDICA (Ukraine). The statistical data was processed using «STATISTICA ${ }^{\circledR}$ for Windows 6.0» (StatSoft Inc., \#AXXR712D833214FAN5).

Results: The hypertensive state is characterized by an excess of the target values of systemic blood pressure: the daily mean values of systolic blood pressure (SBP) and diastolic blood pressure (DBP) were higher at $6,93 \%(P<0,05)$ and 5,68\% $(P<0,01)$ respectively in both groups. Indicators of pressure increase and morning surge $(M S)$ are significant in patients of the second clinical group exclusively $S B P$, namely: the index of time (IT) - by 24,68\% (P<0,01), the index of measurements (IM) - by 16,84\% $(P<0,05), M S-$ by $31,98 \%(P<0,01)$.

Conclusions: The practice of application of daily arterial blood pressure and ECG monitoring has an important prognostic value in cardiovascular system functional status estimation and also enables the physician in optimising the treatment plan accordingly.

Keywords: hypertension, monitoring, blood pressure, ambulatory, electrocardiography. 
Vamsi et al. : Combination approach with ambulatory Blood Pressure and Electrocardiography Monitoring in Patients with Hypertension and Myocardial Infarction - A Prospective Study.

\section{INTRODUCTION}

Arterial hypertension $(\mathrm{AH})$ is one of the most frequent cardiovascular pathology, being the most important cause of disability and premature mortality due to a number of complications [1]. According to the World Health Organization information, there are currently more than 1 billion people suffering from hypertension [2]. Based on modern concepts, the prognosis of patients with

hypertension depends not only on the level of arterial blood pressure (BP), but also on the presence of structural and functional changes in target organs, the available risk factors and the concomitant clinically significant states as well [3].

Office blood pressure measurements do not reflect the true blood pressure values. Keeping in mind the phenomenon of white coat in which the patient shows an increase in blood pressure values in the office, whereas the blood pressure at home will be normal or less than that measured at the Physician's vicinity. With the introduction of 24 hour Ambulatory blood pressure monitoring in the 20 th century, it was initially a burden to introduce these devices in the clinics due to their heavy size. But, later they were upgraded into a smaller lightweight and easy to use machine, which play a very important role in the treatment modulation in patients with hypertension.

To date, ambulatory blood pressure monitoring $(\mathrm{ABPM})$ is the most reliable and informative way of $\mathrm{AH}$ diagnosis as well as the evaluation of the effectiveness of antihypertensive therapy, for investigating the functional state of the cardiovascular system -, which makes it possible to assess as traditional one-time measurement usingdaily BP profile [4].24 hour electrocardiogram (HECG) is a highly sensitive and specific method by which daily observation of cardiac activity of a patient is performed. The relevance of this non- invasive method is that it allows to detect any functional changes of cardiovascular system in the early stages of their development, helps toidentifysilent myocardial ischemia and detect any rhythm and conductivity disorders [5].

There are several applications of ABPM apart from predicting future target organ damage, it also gives the physician data about morning surge of blood pressure and night surge, this further classifies the patients into dipper and non-dipper [6].

The modern guidelines from the National institute for Health and Clinical excellence on management of hypertension, suggested using ABPM for confirmation of the clinical diagnosis if the values of the BP is $\geq 140 / 90 \mathrm{mmHg}$ [7].

The purpose of the study: To examine the functional state of cardiovascular system and possible predictive value of the daily application of the combined method of arterial blood pressure monitoring and ECG monitoring in hypertensive patients at different levels of the disease progression.

Materials and methods: We examined 37 patients with $\mathrm{AH}$ without any clinical significant pathology were included in the first group and 32 hypertensive patients with a history of myocardial infarction (MI) in the second group. The average age of participants in this study was $59,02 \pm 2,18$ years. Both groups

were comparable in terms of gender, age, duration and severity of the underlying disease. This study was approved by the Institutional ethics committee of the Zaporozhye State Medical University, Ukraine.

All patients underwent a comprehensive examination of the functional state of the cardiovascular system using the combined ECG and arterial BP monitoring validated device «CardiosensBP»XAIMEDICA(Ukraine). We used a proper sized cuff to avoid any errors pertaining to cuff arm compliance. An informed consent was obtained from all the individuals who participated in the study.

All the statistical data were carried out using recommended methods for medical-biological research in accordance with the criteria of evidencebased medicine [8]. The results of the study were 
Vamsi et al. : Combination approach with ambulatory Blood Pressure and Electrocardiography Monitoring in Patients with Hypertension and Myocardial Infarction - A Prospective Study.

Table 1: Indicators of DBPM in hypertensive patients

\begin{tabular}{|c|c|c|c|c|}
\hline \multirow[t]{2}{*}{ Indicators } & \multicolumn{2}{|l|}{$\begin{array}{l}\text { Patients } \\
(\mathrm{n}=37)\end{array}$} & \multicolumn{2}{|c|}{ Patients with MI $(n=32)$} \\
\hline & & $\mathrm{DBP}$ & & DBP \\
\hline & 1 & 2 & 3 & 4 \\
\hline \multirow{4}{*}{$\begin{array}{l}\text { Mean values, } \\
\mathrm{mmHg} \\
\mathrm{IT}, \%\end{array}$} & \multirow[t]{2}{*}{$157,21 \pm 4,35$} & \multirow[t]{2}{*}{$89,12 \pm 1,36$} & $168,11 \pm 7,04$ & $94,18 \pm 0,6$ \\
\hline & & & $\mathrm{P} 1-3<0,05$ & $\mathrm{P} 2-4<0,01$ \\
\hline & \multirow{2}{*}{$54,17 \pm 2,49$} & \multirow{2}{*}{$44,85 \pm 2,01$} & $67,54 \pm 4,21$ & $49,15 \pm 3,82$ \\
\hline & & & $\mathrm{P} 1-3<0,01$ & $\mathrm{P} 2-4>0,05$ \\
\hline \multirow[t]{2}{*}{$\mathrm{IM}, \%$} & \multirow[t]{2}{*}{$44,23 \pm 4,04$} & \multirow[t]{2}{*}{$41,25 \pm 1,17$} & $51,68 \pm 1,09$ & $42,94 \pm 1,04$ \\
\hline & & & $\mathrm{P} 1-3<0,05$ & $\mathrm{P} 2-4>0,05$ \\
\hline \multirow[t]{2}{*}{ DI, \% } & \multirow[t]{2}{*}{$4,15 \pm 0,18$} & \multirow[t]{2}{*}{$8,04 \pm 0,94$} & $2,84 \pm 0,25$ & $5,18 \pm 1,37$ \\
\hline & & & $\mathrm{P} 1-3<0,05$ & $\mathrm{P} 2-4<0,05$ \\
\hline \multirow{4}{*}{$\begin{array}{l}\text { Variability, } \\
\mathrm{mmHg} \\
\mathrm{MIS}, \\
\mathrm{mmHg} / \text { hour }\end{array}$} & \multirow{2}{*}{$18,25 \pm 4,34$} & \multirow[t]{2}{*}{$15,18 \pm 0,25$} & $29,4 \pm 4,28$ & $18,24 \pm 1,37$ \\
\hline & & & $\mathrm{P} 1-3<0,05$ & $\mathrm{P} 2-4<0,05$ \\
\hline & \multirow[t]{2}{*}{$17,01 \pm 1,14$} & \multirow[t]{2}{*}{$6,05 \pm 1,25$} & $22,45 \pm 0,97$ & $7,62 \pm 1,09$ \\
\hline & & & $\mathrm{P} 1-3<0,01$ & $\mathrm{P} 2-4>0,05$ \\
\hline
\end{tabular}

Table 2: Results of DM ECG in hypertensive patients

\begin{tabular}{lllll}
\hline \multirow{2}{*}{ Indicators } & $\begin{array}{l}\text { Patients } \\
(\mathrm{n}=37)\end{array}$ & without & MI & Patients with MI $(\mathrm{n}=32)$ \\
& $\mathrm{VE}$ & $\mathrm{SVE}$ & $\mathrm{VE}$ & $\mathrm{SVE}$ \\
& 1 & 2 & 3 & 4 \\
Single PB & $127,5 \pm 3,14$ & $78,16 \pm 4,2$ & $131,17 \pm 2,12$ & $69,78 \pm 5,33$ \\
& & & $\mathrm{P} 1-3>0,05$ & $\mathrm{P} 2-4>0,05$ \\
Coupled PB & $45,21 \pm 7,39$ & $92,45 \pm 1,95$ & $89,57 \pm 11,85$ & $101,65 \pm 2,84$ \\
& & & $\mathrm{P} 1-3<0,01$ & $\mathrm{P} 2-4<0,05$ \\
Group PB & $34,17 \pm 4,53$ & $14,84 \pm 1,82$ & $42,31 \pm 3,41$ & $37,21 \pm 4,95$ \\
& & & $\mathrm{P} 1-3<0,01$ & $\mathrm{P} 2-4<0,01$ \\
Bigeminy & $34,08 \pm 4,35$ & $14,2 \pm 2,31$ & $57,24 \pm 4,68$ & $11,23 \pm 2,4$ \\
& & & $\mathrm{P} 1-3<0,05$ & $\mathrm{P} 2-4>0,05$ \\
Trigemini & $40,21 \pm 5,4$ & $7,02 \pm 0,84$ & $54,39 \pm 4,66$ & $9,34 \pm 1,5$ \\
& & & $\mathrm{P} 1-3<0,01$ & $\mathrm{P} 2-4>0,05$ \\
Quadrigeminy & $67,14 \pm 4,65$ & $24,05 \pm 3,1$ & $84,11 \pm 7,17$ & $27,5 \pm 2,24$ \\
& & & $\mathrm{P} 1-3<0,05$ & $\mathrm{P} 2-4>0,05$ \\
\hline
\end{tabular}


Vamsi et al. : Combination approach with ambulatory Blood Pressure and Electrocardiography Monitoring in Patients with Hypertension and Myocardial Infarction - A Prospective Study.

processed using the $\ll$ STATISTICA ${ }^{\circledR}$ for Windows 6.0» (StatSoft Inc., \#AXXR712D833214FAN5).

Statistically significant differences were considered at $\mathrm{P}<0,05$.

Results: The analysis of the data showed that in hypertensive patients with MI a majority of studied parameters were consistently higher than in first clinical group . Thus, the state of hypertension is characterized by an excess of the target values of systemic blood pressure: the daily mean values of systolic blood pressure (SBP) and diastolic blood pressure (DBP) were higher at $6,93 \%$ $(\mathrm{P}<0,05)$ and 5,68\% $(\mathrm{P}<0,01)$ respectively in both groups.

Indicators of pressure loading and morning surge (MS) are significant in patients of the second clinical group exclusively SBP, namely: the index of time (IT) - by $24,68 \%(\mathrm{P}<0,01)$, the index of measurements (IM) - by 16,84\% $(\mathrm{P}<0,05)$, MS by $31,98 \%(\mathrm{P}<0,01)$. These changes correspond to a sufficiently stable systolic hypertension, more pronounced among the group of patients, which adversely affects the potential risk of increasingthe recurrence of cardiovascular episodes.

The dynamics of systemic BP indices throughout the day in all patients with hypertension was characterized by a lack of adequate night-time drop, which resulted in the formation of a specific profile-«non-dipper», with a tendency towards SBP more negative. Transferred in the past MI was reflected in a significant decrease of the daily index (DI) for SBP by 46,13\% $(\mathrm{P}<0,05)$ and DBP - by $55,21 \%(\mathrm{P}<0,05)$. The indicated changes in the hemodynamic profile, characterizing the functional state of the cardiovascular system, were reflected in a significant increase of the variability of both and DBP in the second group of observation by $61,6 \%(\mathrm{P}<0,05)$ and $20,16 \%(\mathrm{P}<0,05)$ respectively, being as additive factor in an adverse cardiovascular continuum.

According to the results of the DM ECG, it has been established that the presence of hypertension is associated with the appearance of the following clinically significant heart rhythm disturbances. With a comparable number of single ventricular and supraventricular episodes (VE and SVE respectively), the presence of postinfarctive cardiosclerosis is characterized by a significant increase in the average frequency of coupled and group premature beats (PB), more ventricular, as well as a short-term episodes of paroxysmal tachycardia and allorhythmias too, predominantly of ventricular origin.

Based on the regular sinus rhythm, patients from the second clinical group reported a steady increase in the frequency of coupled ventricular and supraventricular PB by $98,12 \%(\mathrm{P}<0,01)$ and 9,94\% $(\mathrm{P}<0,05)$ respectively, group ventricular and supraventricular $\mathrm{PB}$ - by $23,82 \%(\mathrm{P}<0,01)$ and 2,51 times $(\mathrm{P}<0,01)$ respectively.

It was noted that there were no reliable differences in the frequency of registration of supra ventricular allorhythmia in the observation groups ( $\mathrm{P}>0,05)$ and short-term episodes of paroxysmal tachycardia of exclusively supraventricular genesis were characteristic only for patients from the second clinical group.

The frequency of the occurrence of episodes of ventricular bi-, tri- and quadrigeminia in patients with a transmitted MI increased on average by $67,96 \%(\mathrm{P}<0,05), 35,26 \%(\mathrm{P}<0,01)$ and $25,28 \%(\mathrm{P}<0,05)$ respectively, in comparison with the first group of the patients.

\section{CONCLUSIONS:}

1. The presence of postinfarctive cardiosclerosis is characterized by the formation of unfavorable hemodynamic profile and an increase in the incidence of various cardiac arhythmias in hypertensive patients.

2. These changes occur based on the sympathetic activation and can be considered as an adverse predictor of the recurrent cardiovascular events in the pathogenetic evolution of arterial hypertension. 
Vamsi et al. : Combination approach with ambulatory Blood Pressure and Electrocardiography Monitoring in Patients with Hypertension and Myocardial Infarction - A Prospective Study.

3. The routine application of daily arterial blood pressure and ECG monitoring has an important prognostic value in cardiovascular system functional status estimation.

\section{DISCUSSIONS:}

An additional analysis of the cardiac rhythm variability made it possible to establish that there were no reliable differences in the averaged parameters of temporal and spectral characteristics in the observation groups. However, an increase in the potential risk of repeated cardiac events was associated with the tendency to increase the capacity of the low-frequency spectrum during the night period. The indicator characterizing the low-to-high capacity level in the second group was 4,2 and 2,9 in active and passive periods respectively, whereas in patients without a history of MI there were less expressed circadian oscillations in the same indices (2,5 and 2,2 times respectively).

Several studies like Syst-Eur and Eguchi et al described the use of ABPM to predict future cardiovascular events $[9,10]$.

Recently, much importance has been given to chronotherapy by Hermida et al, who described in their study that in patients with refractory hypertension after ABPM, an addition of one antihypertensive drug before sleep to reduce the morning surge, eventually decreasing the changes for cardiovascular event occurrence [11].

Whereas, Ohkubo et al in their prospective study on 1,464 patients showed that ABPM had significantly accurate $\mathrm{BP}$ values in predicting a cerebrovascular accident than traditional office BP measurement [12].

Thus, the formation of an unfavorable hemodynamic profile, associated with postinfarctive remodeling, is characterized by a disturbance in the normal relationship between the functional states of the autonomic nervous system, with a subsequent increase in the activity of sympathetic system.

This strategy not only being cost effective and also reducing misdiagnosis it allows differentiat- ing between white coat phenomenon, white coat hypertension, masked hypertension and resistant hypertension. Higher population studies on the effectiveness of combining halter ECG and ABPM in patients with arterial hypertension and concomitant diseases like stroke, heart failure another cardio-renovascular diseases should be described.

Conflicts of interest: None declared.

Acknowledgments: All authors contributed to acquiring and interpreting the data, reviews and interpreted the data. V.V. And B.V. contributed to collect, interpret and write the manuscript. B.V. Supervised, organized and provided the study materials. A.S, M.V and V.U took care of the responsibility of literature search and contents of the article.

\section{REFERENCES:}

[1] Ermakovich I. I. Prevention of chronic noncommunicable diseases at the population level [Electronic resource] / II Ermakovich, VA Chernyshov // Health of Ukraine. - 2004.Vol. 108. -available at http://www.healthua.org/article/health/892.html

[2] Sirenko Yu. M. Hypertonic Disease / YuM. Sirenko. - K .: Health, 2009. - 240 p. [In Russian]

[3] ESH / ESC Guidelines for Management of Arterial Hypertension. The Task Force for the Management of Arterial Hypertension of the European Society of Hypertension (ESH) and the European Society of Cardiology (ESC) / European Heart Journal. - 2013. - Vol. 34. - p. 2159-2219.

[4] Ryabykina G. V. Bifunctine monitoring of Holter ECG and arterial pressure. Medical Practice - 2010:320. [In Russian]

[5] Makarov L. M. Holter monitoring of ECG. Medpractika - 2008; 3:75. [In Russian]

[6] Grossman E. Ambulatory Blood Pressure Monitoring in the Diagnosis and Management of Hypertension. Diabetes Care. 2013 Aug; 36(Suppl 2): S307-S311.

[7] Krause T, Lovibond K, Caulfield M, McCormack T, Williams B, Guideline Development 
Vamsi et al. : Combination approach with ambulatory Blood Pressure and Electrocardiography Monitoring in Patients with Hypertension and Myocardial Infarction - A Prospective Study.

Group Management of hypertension: summary of NICE guidance. BMJ 2011;343:d4891. [PubMed] [Ref list]

[8] Lyakh Yu, Guryanov V, Khomenko V, Panchenko O. Bases of computer biostatistics: analysis of information in biology, medicine and pharmacy using MedStat statistical package. Donetsk: Papakitsa E.K 2006; 214. [Russian].

[9] Eguchi K, Pickering TG, Hoshide S, et al.Ambulatory blood pressure is a better marker than clinic blood pressure in predicting cardiovascular events in patients with/without type 2 diabetes. Am J Hypertens 2008;21:443-450 [PubMed][Ref list]

[10] Staessen JA, Thijs L, Fagard R, et al. Systolic Hypertension in Europe Trial Investigators
Predicting cardiovascular risk using conventional vs ambulatory blood pressure in older patients with systolic hypertension. JAMA 1999;282:539546 [PubMed] [Ref list]

[11] Hermida RC, Ayala DE, Mojón A, Fernández JR. Influence of time of day of blood pressurelowering treatment on cardiovascular risk in hypertensive patients with type 2 diabetes. Diabetes Care2011;34:1270-1276 [PubMed] [Ref list]

[12] Ohkubo T, Hozawa A, Nagai K, et al. Prediction of stroke by ambulatory blood pressure monitoring versus screening blood pressure measurements in a general population: the Ohasama study. J Hypertens 2000;18:847-854 [PubMed] [Ref list] 